- Review Article

\title{
Cigarette Smoking in South Korea: A Narrative Review
}

\author{
Rebekah Gunter ${ }^{1, *}$, Edwin Szeto', Se-Hoon Jeong' ${ }^{2}$, Sooyeon (Aly) Suh ${ }^{3}$, Andrew J. Waters' \\ 'Department of Medical and Clinical Psychology, Uniformed Services University of the Health Sciences, Bethesda, MD, USA \\ ${ }^{2}$ School of Media \& Communication, Korea University, Seoul, Korea \\ ${ }^{3}$ Department of Psychology, Sungshin Women's University, Seoul, Korea
}

\begin{abstract}
Although the prevalence of cigarette smoking has declined in Western countries over the past few decades, a comparable decline among males has not been observed in Asian countries, especially in South Korea, where approximately $40 \%-50 \%$ of men and $4 \%-8 \%$ of women have been identified as smokers, and there is a pressing need to understand the background of cigarette smoking in these populations. The present study is a narrative review of the research literature on cigarette smoking in South Korea. First, we describe the social, economic, and cultural factors that impact cigarette smoking in South Korea. The paper also reviews the available peer-reviewed literature comprising observational studies and interventional studies, including randomized controlled trials. The extant literature on smoking in Korean Americans is also reviewed. Cigarette smoking in South Korea has been relatively understudied, and this review identifies priority areas for future research, including the use of mobile interventions.
\end{abstract}

Keywords: Cigarette Smoking; Smoking; Republic of Korea; Asia

\footnotetext{
Received: February 2, 2018, Revised: August 17, 2018, Accepted: September 10, 2018

${ }^{*}$ Corresponding Author: Rebekah Gunter https://orcid.org/0000-0002-7315-2238

Tel: +1-513-207-3246, Fax: +1-301-295-3034,E-mail: rebekah.gunter@usuhs.edu

tWork was conducted in the Department of Medical and Clinical Psychology, Uniformed Services University of the Health Sciences.
} 


\section{INTRODUCTION}

Cigarette smoking remains a major global health concern. Although the proportion of smokers has decreased worldwide, the total number of smokers has increased due to the population growth. ${ }^{1)}$ In 2012, an estimated 967 million people smoked daily compared to 721 million in $1980{ }^{2)}$ Approximately six million people worldwide die due to tobacco-related diseases each year. ${ }^{3)}$ Smoking is associated with increased risk of many adverse health conditions, including cardiovascular disease, several types of cancers and stroke. ${ }^{4)}$ Out of the estimated six million people who die each year, 600,000 people die due to secondhand smoking.

Despite the well-known health risks associated with cigarette smoking and the decreased prevalence of smoking in countries such as the United States, a high prevalence is still observed in East Asian countries, particularly among males. ${ }^{3,4)}$ Although there is evidence of overall reduction in the smoking prevalence over time in part of the East Asian countries, smoking appears to be increasing (or not decreasing) within some subpopulations, which has resulted in increased prevalence of adverse health conditions associated with smoking, such as cancer. ${ }^{5,6)}$

\section{CIGARETTE SMOKING IN SOUTH KOREA}

Multiple surveys have estimated the smoking prevalence in South Korea. According to the 2017 report of the World Health Organization (WHO), approximately $49.8 \%$ of Korean adult males and $4.2 \%$ of Korean adult females were found to be smokers in 2015. ${ }^{3)}$ The 2015 report of the Organization for Economic Cooperation and Development (OECD) found a smoking prevalence of $31.1 \%$ and $3.4 \%$ in males and females, respectively. ${ }^{7}$ Of note, the WHO estimates include both daily and non-daily smokers, while the OECD estimates include only daily smokers. Additionally, the WHO estimates use a regression analysis to compare the prevalence among countries; thus, it possibly differs from the OECD estimates due to differences in the geographic coverage and adjustments for other variables. Moreover, the Korea National Health and Nutrition Examination Survey (KNHANES) report, addressing the period from 2008 to 2011, indicated, through measurements of urinary cotinine concentration, that the smoking prevalence in South Korea tends to be underestimated when based on self-reports. Specifically, the prevalence based on urinary cotinine results proved to be increased by 5.0 percentage points among males ( $52.7 \%$ versus $47.7 \%$ ), and more than doubled among females (15.4\% versus $6.8 \%$ ), when compared to the prevalence based on self-reports. ${ }^{8}$ Another KNHANES report found that the prevalence rates of smoking among male and female adults (aged 19 years or older) in 2016 were $40.7 \%$ and $6.4 \%$, respectively, being therefore lower than those in the 20082011 survey. Between 2011 and 2016, the lowest smoking prevalence rates among male and female adults (39.4\% and $5.5 \%$, respectively) were observed in 2015. ${ }^{9)}$ In addition, there is evidence that the smoking prevalence can be increasing in other populations. The Institute for Health Metrics and Evaluation reported an increased prevalence among adolescents and young female adults from 1980 to $2014 .{ }^{1)}$ In 2016, the prevalence of cigarette smoking among Korean adolescent males was $9.6 \%$, while the prevalence among Korean adolescent females was $2.7 \%$. $^{3)}$

Although life expectancy in South Korea is one of the longest among industrialized countries, the high prevalence of tobacco smoking among South Korean males poses an interesting research question. ${ }^{10)}$ There are many contributing factors for such increased prevalence, including the historically low cost of cigarettes (approximately US \$2.20 per pack), the relatively scarce anti-smoking campaigns and legislations, and social factors that encourage smoking. ${ }^{11)}$ In addition, the recent emergence of electronic nicotine delivery systems (ENDS, e-cigarettes), which have been extensively marketed, is an additional challenge. $^{12)}$

\section{TOBACCO CONTROL IN KOREA}

Historically, anti-smoking health care policies have not been as aggressively promoted in South Korea as in other countries. ${ }^{13)}$ Fewer than $60 \%$ of Koreans express interest in quitting smoking and indifference is an obstacle to successfully driving smoking cessation and lowering smoking prevalence. ${ }^{14,15)}$ Additionally, there are limited legislations regarding e-cigarettes, which are potentially harmful products. ${ }^{16)} \mathrm{Al}$ though the policies for tobacco and ENDS seem separate, the disseminated use of e-cigarettes may normalize the nicotine use in general and impair the progress obtained by tobacco control campaigns.

However, South Korea has recently implemented multiple antismoking regulations in order to reduce the rates of tobacco addiction. These regulations include inflation in the cigarette cost (from US $\$ 2.20$ to US $\$ 4.22$ per pack), increased taxation of tobacco products, implementation of smoke-free public spaces, and banning of tobacco advertisements in stores. ${ }^{17,18)}$ In 2016, South Korea implemented a policy requiring depiction of graphical health warnings in all cigarette packages. ${ }^{18)}$ As many of these regulations are relatively new, it is difficult to estimate their current impact on the prevalence of tobacco smoking in South Korea.

The Framework Convention on Tobacco Control (FCTC) was responsible for a significant impact on the decline of the smoking prevalence worldwide. The FCTC was established in 2005 and about 150 countries have implemented several policies for tobacco control, including increased taxation of tobacco products, implementation of smoke-free public places, packaging regulations, and public awareness campaigns. While, as aforementioned, Korea has strengthened its own tobacco control policies to align with the FCTC; Lim and Cho ${ }^{19)}$ state that such policies can be improved. For example, the price of the cigarette pack, although more expensive than in the past, is still low, considering the nation's income. Furthermore, tobacco advertisements are only partially restricted and workplace smoking policies are limited to larger companies. 


\section{GENDER AND SMOKING IN SOUTH KOREA}

The pattern of smoking prevalence in South Korea is similar to that observed in other non-Western countries, where the smoking prevalence is typically higher in males than in females. ${ }^{1)}$ In addition, there is concern about the non-reduction (and a possible increase) in the smoking prevalence among South Korean women. The exact prevalence in this particular population is difficult to calculate, especially when it comes to married women, among whom the prevalence may be underreported, as they are socially discouraged and restricted from smoking, while Korean women who do not feel restricted by social pressures (e.g., those who are divorced, unmarried, widowed, etc.) may smoke more frequently. ${ }^{20,21)}$ The smoking rate in the unmarried female population is higher, suggesting marriage as a protective factor for many Korean females. ${ }^{22)}$ In addition, education level and occupation are predictors of smoking in females. ${ }^{23)}$

Due to the changing social environment, gender has become a more important variable in the smoking problem in South Korea. The rapid industrialization and urbanization in South Korea resulted in improved educational attainment (6.6 to 10.5 years) among women. ${ }^{23)}$ Such changes may induce other social changes, especially regarding socioeconomic positions. ${ }^{24)}$ With the changing female role in society, women may become more prone to smoking.

\section{SOCIOCULTURAL FACTORS}

South Korea's significant economic growth has resulted in widespread social changes. Market liberalization has opened the access of transnational tobacco companies (TTCs) to previously closed markets, and, as a result, many TTCs have targeted the South Korea's potential market. ${ }^{25,26)}$ Despite the existing legislation to regulate the TTCs' marketing, TTCs indirectly target specific populations of South Korea (e.g., women and young adults), increasing the risk of smoking in these populations.

Another important issue in South Korea is the association between military service and smoking. South Korean veterans are more likely to be regular smokers than their civilian counterparts. ${ }^{27)}$ Anecdotally, veterans from the South Korean military force describe the military service as a period that strongly influenced them to initiate and maintain smoking. Many service members smoke due to the free cigarette distribution and its use as a social activity. ${ }^{27)}$ This is a social factor that influences the prevalence of tobacco smoking among South Korean men, ${ }^{28)}$ as military service is only mandatory for men. ${ }^{29)}$

The role of effect of smoking in South Korea also needs to be considered. In Western countries, there is an association between negative affect (e.g., stress and relapse) and smoking. ${ }^{30)}$ In East-Asian countries, the dialectic nature of the Asian thinking may influence how Asians experience and report positive and negative affect. ${ }^{31-33)}$ Thus, the findings about association between affect and smoking documented in Western populations may not seamlessly applicable to an East Asian population.

\section{METHODS}

This narrative review article aimed to describe and discuss the current literature on smoking in the Korean and Korean American (KA) populations. The literature search was conducted using the Pubmed (US National Library of Medicine, National Institutes of Health) database, with the following terms: 'Korean smoking, 'Korean anti-smoking,' 'Korean smoking and gender,' 'Korean smoking randomized control trial,' and 'Korean smoking cessation programs.' Studies were also identified using secondary citations, a general web browser (e.g., Google Scholar), and after a secondary search using broader search terms. Studies on the main themes of this narrative review published in English between 2000 and 2017 were included. Studies on smoking among KAs were also reviewed, as this may partly reflect the sociocultural influences on South Koreans. The focus on English-language publications is a limitation, although there is little evidence that the exclusion of non-English language studies from reviews results in biased conclusions. ${ }^{34)}$

\section{REVIEW}

We reviewed pertinent observational (Table 1) and interventional studies (Table 2) on smoking in South Korea. The potential utility of field studies using ecological momentary assessment (EMA) was also evaluated, followed by a review of studies examining the prevalence of tobacco smoking among KAs (Table 3).

\section{OBSERVATIONAL STUDIES}

As indicated in Table 1, most identified observational studies were cross-sectional. Studies examined both adolescent and adult smokers, and focused on factors associated with smoking initiation or smoking cessation (or related variables, such as intention to quit smoking). One study used a statistical model (SimSmoke) to examine trends in smoking over time. ${ }^{5)}$

Korean adolescents comprise a population of interest for several reasons. In addition to the high prevalence of smoking in this age group, such habit leads to developmental consequences, including early onset of chronic obstructive pulmonary disease and other subsequent health concerns. ${ }^{35)}$ The Korea Centers for Disease Control and Prevention has monitored trends in smoking through a national health survey, known as the KNHANES. ${ }^{36)}$ Many researchers have used this dataset to study smoking in specific populations, such as adolescents and females.

Despite the Youth Protection Act having forbidden tobacco sales to adolescents, there is a high rate of smoking among Korean adolescents, ${ }^{36)}$ and a study found that $28 \%$ of the adolescent smokers reported having tried their first cigarette in the ninth grade. ${ }^{37)}$ Moreover, Korean adolescents start smoking at a mean age of 13.5 years. Among high-school students from the city of Daegu, the reported smoking prevalence was about $18 \%$. This rate is concerning, since smoking ini- 


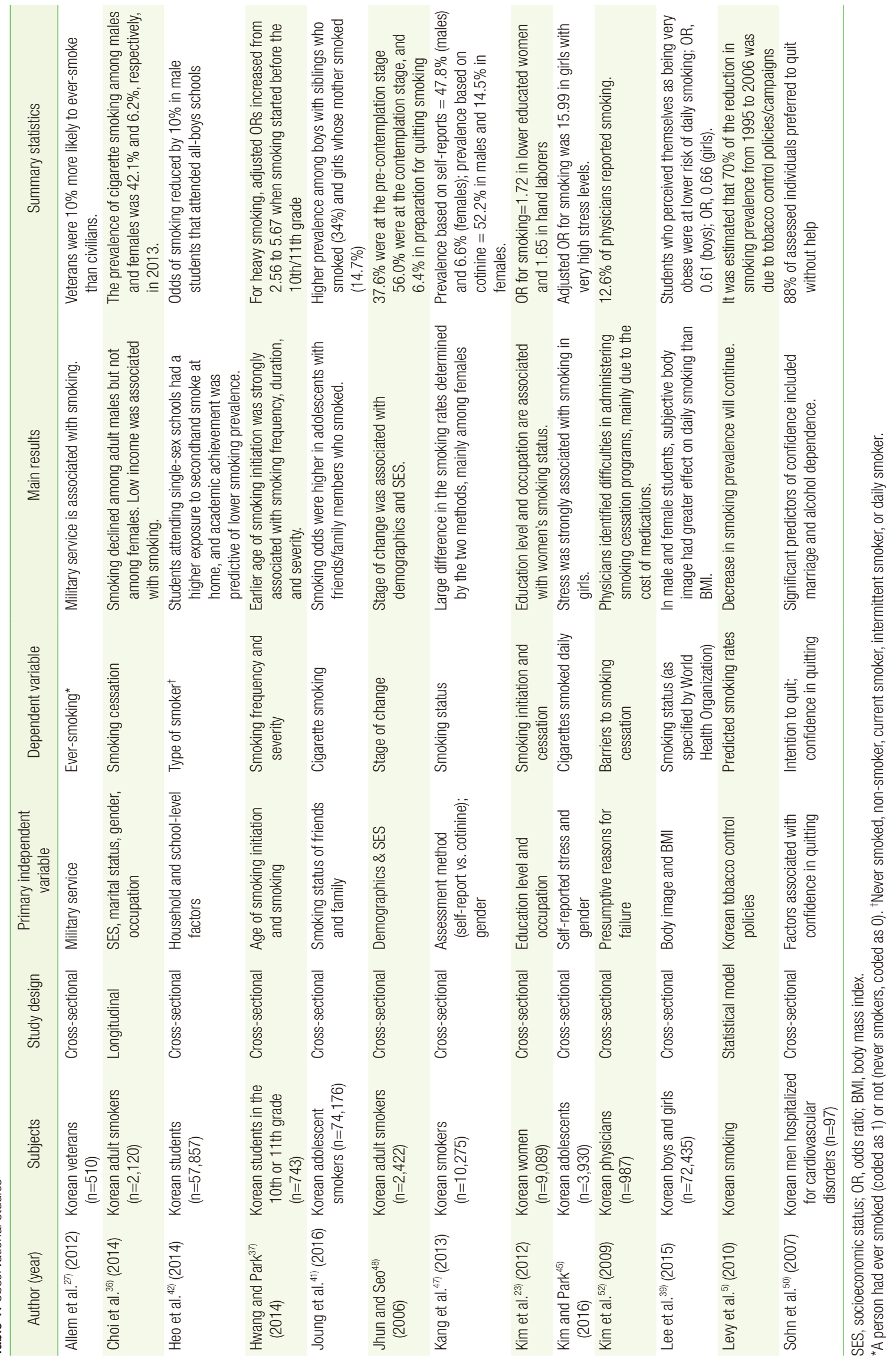


Table 2. Interventional studies

\begin{tabular}{|c|c|c|c|c|c|}
\hline Author/year & Subjects & Study design & Primary independent variable & Dependent variable & Main results \\
\hline $\begin{array}{l}\text { Choi et al. }{ }^{54)} \\
\text { (2013) }\end{array}$ & $\begin{array}{l}\text { Male smokers }>19 \text { years } \\
\text { old }(n=95)\end{array}$ & $\begin{array}{l}\text { Controlled trial using } \\
\text { cluster sampling }\end{array}$ & Education and self-help & $\begin{array}{l}\text { No. of cigarettes smoked; } \\
\text { motivation to quit }\end{array}$ & $\begin{array}{l}\text { Educational sessions led to increased } \\
\text { motivation to quit, but not to successful } \\
\text { cessation. }\end{array}$ \\
\hline $\begin{array}{l}\text { Hwang et al. }{ }^{68)} \\
\text { (2012) }\end{array}$ & $\begin{array}{l}\text { Male Korean workers } \\
\quad(n=58)\end{array}$ & Pre-post intervention & $\begin{array}{l}\text { The intervention was an } \\
\text { incentive-based intervention } \\
\text { (i.e., fitness center as } \\
\text { incentive) for promoting } \\
\text { smoking cessation } \\
\text { maintenance. }\end{array}$ & Cessation; cotinine levels & $\begin{array}{l}\text { Intervention was moderately successful in } \\
\text { promoting smoking cessation; } 53.2 \% \text { of } \\
\text { individuals reported cessation for } 3 \\
\text { months. }\end{array}$ \\
\hline $\begin{array}{l}\text { Kim et al. }{ }^{56)} \\
(2016)\end{array}$ & $\begin{array}{l}\text { Korean adolescents } \\
(\mathrm{n}=379)\end{array}$ & Pre-post intervention & $\begin{array}{l}\text { Intervention for smoking } \\
\text { cessation; subgroups } \\
\text { identified by analyses }\end{array}$ & Cessation; cotinine levels & $\begin{array}{l}\text { Classification and regression tree analyses } \\
\text { identified characteristics of subgroups } \\
\text { with low (no intention to quit; started } \\
\text { smoking after 8th grade) and high } \\
\text { smoking cessation rates. }\end{array}$ \\
\hline $\begin{array}{l}\text { Myung et al. }{ }^{57} \\
(2011)\end{array}$ & $\begin{array}{l}\text { Koreans who called the } \\
\text { quitline }(n=3,631)\end{array}$ & Pre-post intervention & $\begin{array}{l}\text { Tele-delivered } 30 \text {-day smoking } \\
\text { cessation program and short } \\
\text { message service }\end{array}$ & $\begin{array}{l}\text { Self-reported cessation } \\
\text { status }\end{array}$ & $\begin{array}{l}\text { Predictors of smoking cessation included } \\
\text { male gender, older age, holding } \\
\text { occupational medical insurance, and low } \\
\text { Framework Convention on Tobacco } \\
\text { Control scores. }\end{array}$ \\
\hline $\begin{array}{l}\text { Lee et al. }{ }^{55)} \\
(2016)\end{array}$ & $\begin{array}{l}\text { Patients seen at Health } \\
\text { Screening Center of } \\
\text { Seoul National University } \\
\text { Hospital }(\mathrm{n}=414)\end{array}$ & $\begin{array}{l}\text { Clustered } \\
\text { randomized control } \\
\text { trial }\end{array}$ & $\begin{array}{l}\text { Application of decision aid } \\
\text { presentation (7-minute video) }\end{array}$ & $\begin{array}{l}\text { Prescription of medication } \\
\text { for cessation and } \\
\text { abstinence rates }\end{array}$ & $\begin{array}{l}\text { Decision aid did not significantly affect the } \\
\text { use of medication or smoking cessation. }\end{array}$ \\
\hline
\end{tabular}

Table 3. Studies with Korean Americans

\begin{tabular}{|c|c|c|c|c|c|}
\hline Author/year & Subjects & Study design & $\begin{array}{l}\text { Primary independent } \\
\text { variable }\end{array}$ & Dependent variable & Main results \\
\hline $\begin{array}{l}\text { Cerrada et al. }{ }^{64)} \\
\text { (2016) }\end{array}$ & $\begin{array}{l}\text { Korean American } \\
\text { emerging adults } \\
(\mathrm{n}=475)\end{array}$ & Cross-sectional & $\begin{array}{l}\text { Demographic and } \\
\text { smoking variables }\end{array}$ & $\begin{array}{l}\text { Perceived smoking } \\
\text { prevalence }\end{array}$ & $\begin{array}{l}\text { Respondents, especially females, tended to } \\
\text { overestimate the smoking prevalence, particularly } \\
\text { when they were current smokers. }\end{array}$ \\
\hline $\begin{array}{l}\text { Cerrada et al. }{ }^{65)} \\
\text { (2016) }\end{array}$ & $\begin{array}{l}\text { Korean American } \\
\text { emerging adults } \\
(n=78)\end{array}$ & 7-Day EMA protocol & Contextual variables & Cigarette smoking & $\begin{array}{l}\text { Participants were more likely to smoke outside, in } \\
\text { the presence of Korean friends (without family } \\
\text { presence), while socializing, and during momentary } \\
\text { stress }\end{array}$ \\
\hline $\begin{array}{l}\text { Cerrada et al. }{ }^{67} \\
\text { (2017) }\end{array}$ & $\begin{array}{l}\text { Korean American } \\
\text { emerging adults }(n=8)\end{array}$ & $\begin{array}{l}\text { Focus group and } \\
\text { semi-structured } \\
\text { interviews }\end{array}$ & NA & $\begin{array}{l}\text { Perceptions of smoking } \\
\text { and smoking cessation } \\
\text { strategies; causes of } \\
\text { relapse }\end{array}$ & $\begin{array}{l}\text { Smoking episodes are driven by context, requiring } \\
\text { personalized treatment; the study will implement a } \\
\text { just-in-time adaptive intervention-based } \\
\text { assessment. }\end{array}$ \\
\hline $\begin{array}{l}\text { Huh et al. }{ }^{44)} \\
\text { (2014) }\end{array}$ & $\begin{array}{l}\text { Korean American } \\
\text { emerging adults } \\
(\mathrm{n}=22)\end{array}$ & 7-Day EMA protocol & $\begin{array}{l}\text { Contextual and affect } \\
\text { variables }\end{array}$ & Cigarette smoking & $\begin{array}{l}\text { Momentary negative affect and being with friends } \\
\text { showed independent association with increased } \\
\text { likelihood of smoking. }\end{array}$ \\
\hline $\begin{array}{l}\text { Myung et al.66) } \\
(2010)\end{array}$ & $\begin{array}{l}\text { Korean American males } \\
(\mathrm{n}=387)\end{array}$ & Cross-sectional & Smoking restrictions & Intention to quit & $\begin{array}{l}\text { Household smoking restrictions were associated with } \\
\text { intention to quit smoking. }\end{array}$ \\
\hline $\begin{array}{l}\text { Kim et al. }{ }^{28)} \\
(2005)\end{array}$ & $\begin{array}{l}\text { Korean American males } \\
(\mathrm{n}=22)\end{array}$ & Focus group & NA & $\begin{array}{l}\text { Time of smoking } \\
\text { initiation; smoking in } \\
\text { the United States; } \\
\text { strategies for smoking } \\
\text { cessation }\end{array}$ & $\begin{array}{l}\text { Factors such as cultural pressure, social stigma, } \\
\text { gender identity, and social medium were identified. } \\
\text { Participants reported that it is easier to quit } \\
\text { smoking in the United States than in South Korea. }\end{array}$ \\
\hline
\end{tabular}

EMA, ecological momentary assessment; NA, not applicable.

tiation at earlier ages is associated with subsequent nicotine dependence. ${ }^{38)}$ Moreover, Korean adolescents who attend co-educational and/or vocational schools are more likely to be smokers, ${ }^{37)}$ although the factors that drive this association are unclear.

Korean adolescents report that they smoke because it is enjoyable, relaxing, and affords them a feeling of independence from their parents. Some adolescents also report that they smoke to manage weight, a highly relevant factor in a culture where women are very body con- scious. $^{39,40)}$ In addition, the smoking habit (including the use of e-cigarettes) of family members and friends showed to be positively associated with the smoking behavior in adolescents, ${ }^{41)}$ emphasizing the role of relationships in this behavior.

Many residents of East-Asian countries report high levels of perceived stress, and the association between stress and smoking has been reported. ${ }^{42-44)}$ In particular, Korean adolescents usually report high levels of stress due to academic and social demands, with suicide 
being the leading cause of death in this population. ${ }^{45)}$ While the association between stress and smoking is well known, there is evidence of such relationship among Korean boys and girls as young as 12 years old. ${ }^{45)}$ Notably, the smoking prevalence was shown to be higher in girls who reported high stress levels than in boys who reported the same.

As above mentioned, the stigma surrounding smoking among Korean women makes it more difficult to study this high-risk population. Since Korean women are less likely to disclose their smoking habits, the smoking prevalence among them is likely to be higher than that indicated by self-reports. ${ }^{46)}$ Studies analyzing biochemical markers of smoking, such as salivary levels of cotinine (a breakdown product of nicotine) support this speculation. KNHANES data were analyzed to compare the rates of smoking among Korean women based on self-reports and measurements of cotinine levels. The latter proved to be $9 \%$ higher than the prevalence based on self-reports. ${ }^{47)}$ Data suggested that family status (e.g., living with multiple generations under one roof) was a predictor of inaccurate report, supporting the hypothesis that smoking is a socially undesirable behavior for women in South Korea.

A research suggested that most South Korean adult smokers are not prepared to quit. ${ }^{48)}$ Based on the transtheoretical stages of change of Prochaska and DiClemente, ${ }^{49)} 37.6 \%$ reported to be in the pre-contemplation stage, and $56.0 \%$ reported to be in the contemplation stage. Moreover, a high percentage of Korean males (87.8\%) reported that they would rather attempt to quit by themselves instead of using specific smoking cessation tools. ${ }^{50)}$ These factors are barriers to the successful smoking cessation in adult smokers.

Another topic of concern is future changes in the prevalence of tobacco smoking. As early mentioned, the evidence support that smoking prevalence may not be decreasing in females and adolescents. On the other hand, the 'SimSmoke' model, a statistical model that accurately predicted the $24 \%$ relative reduction in the smoking prevalence from 1995 to 2006, continues to predict an overall decrease in smoking as tobacco control policies, taxation on tobacco products, and campaigns have become more popular in South Korea. ${ }^{5)}$ SimSmoke provides estimates of smoking trajectories based on policies and trends observed in recent years. However, adolescents and women may be influenced by other factors that are not incorporated in the model, and the smoking prevalence may be actually increasing among these populations.

Finally, the EMA is an emerging methodology that has been widely used in the smoking research. EMA differs from standard laboratory procedures because it allows real-time data collection in the participants' natural environment. ${ }^{51)}$ While laboratory studies allow researchers to control many extraneous variables, increasing internal validity, EMA studies yield datasets with higher external validity. EMA allows the collection of large amounts of individual data, as well as idiographic (single-subject) analyses. In the smoking research, EMA is an important methodology as it enables researchers to learn which circumstances can drive the craving to smoke or the smoking habit. ${ }^{30)}$ No EMA studies involving South Korean smokers were found in this litera- ture review.

\section{INTERVENTIONAL STUDIES}

As indicated in Table 2, few interventional studies were found, which included a small number of randomized controlled trials. Notably, no trials examining the efficacy of medications for smoking cessation in South Korean smokers were found. In general, interventional studies may be difficult to carry out in South Korea due to the reticence of Koreans when it comes to treatment-seeking behaviors. ${ }^{52)}$ Reluctance to seek medical or psychological support is a barrier to successful cessation programs. People in East Asia may be more likely to seek alternative medicine rather than other treatment approaches. ${ }^{52)}$ Indeed, as above mentioned, $87.8 \%$ of the Korean male smokers reported that they would attempt to quit smoking by themselves rather than use specific smoking cessation tools. ${ }^{50)}$

Western studies have demonstrated that the motivation to quit smoking increases the likelihood of attempting to quit. ${ }^{53)}$ Studies conducted in South Korea have also focused on factors that affect the individual motivation to quit and how they relate to successful smoking cessation. In one study, male smokers were divided into an education group and a control group, using cluster sampling. ${ }^{54)}$ Although the physician-administered educational session was brief (5-10 minutes), a significantly higher level of motivation to quit was observed in the education group. However, the rate of successful cessation did not significantly increase in the same group. Educational programs for smoking require a longer duration, regular sessions, and personalization.

Some studies have used a personalized approach to assess smoking cessation in South Koreans, whereby a culturally-tailored approach was adopted to aid in the decision to quit smoking. ${ }^{55)}$ However, personalized interventions did not have a significant impact on the decision to use medication for smoking cessation. Stage-matched interventions could be an alternative option to personalize interventions for individuals who are not yet prepared to quit smoking. ${ }^{48)}$

Other interventional studies have examined predictors of relapse. This information can be used to identify individuals at risk of poor treatment outcomes. For example, one study examined characteristics of individual groups with low and high smoking cessation rates following intervention. ${ }^{56)}$ They identified seven subgroups through a decision-tree analysis. The subgroup with the lowest smoking cessation rate included individuals who had no intention to quit and who started smoking after the eighth grade. These individuals may require more intensive interventions.

Multiple national studies have been conducted on behalf of the South Korea government to assess the efficacy of quitlines and smoking cessation clinics (SCCs). Researchers have investigated the efficacy of a proactive smoking quitline service center implemented in $18 \mathrm{com}$ munity health centers across South Korea. ${ }^{57)}$ In a large-scale study, they reported that $12.8 \%$ of participants $(n=3,631)$ quit smoking for a continuous period of 12 months. Quitlines may be effective in South Korea, where cell phones are commonly used. As more precisely de- 
scribed below, the use of cell phones, particularly smartphones, provides opportunities for alternative assessments and intervention methodologies using the mobile technology. Public health centers not only facilitate the implementation of quitlines but also house SCCs since 2005.

The effect of acute interventions on smoking can also be observed in laboratory studies. An experimental study conducted in South Korea examined the role of contextual factors on smoking, such as smoking scenes in movies. ${ }^{58)}$ It was found that Korean adolescent males, in particular, were more likely to crave a cigarette after watching a smoking scene.

East Asian researchers have also investigated non-pharmacological, evidence-based cessation therapies, such as acupoint stimulation. ${ }^{59,60)}$ A meta-analysis of 20 English- and Chinese-language studies examined the effect of acupuncture on smoking cessation ${ }^{59)}$ and demonstrated that acupuncture can be an effective therapy. Moreover, a South Korean research has described the mechanism underlying the effect of acupuncture on cue-induced craving. Specifically, acupuncture led to a decreased response to stimuli caused by smoking in certain brain regions (medial prefrontal cortex, premotor cortex, amygdala, and hippocampus), as indicated by functional magnetic resonance imaging. ${ }^{61)}$ Thus, cue-induced cravings are alleviated during the initial abstinence phase of smoking cessation. This approach emerges as a potential secondary alternative for high-risk populations, in which the social stigma is high and treatment seeking is low. On the other hand, a Cochrane review found inconsistent evidence regarding the effect of acupuncture or related techniques on smoking cessation. ${ }^{60)}$

Ecological momentary intervention (EMI) involves delivery of interventions according to the individual's current status. A review of EMI studies in health behavior research indicates that this methodology is commonly used in the context of smoking cessation. ${ }^{62)}$ One EMI study involving behavior modification has been conducted in South Korea, which supports the feasibility of EMI/EMA in South Korea. ${ }^{63)}$ Ecologically-oriented assessments and interventional studies appear to be feasible and effective in many different populations, including KoreanAmericans.

\section{STUDIES ON SMOKING IN KOREAN-AMERICANS}

In the United States, Asian Americans have the lowest reported rate of smoking, when compared to other racial and ethnic groups. ${ }^{64)}$ However, the rate of cigarette smoking among KAs is high when compared to other Asian American groups. Although not all KAs are first-generation immigrants, many of them may still be influenced by the cultural and social pressures that drive the increased smoking rate, as described earlier. The literature addressing studies with KA smokers is also reviewed here (Table 3 ).

Studies have highlighted the importance of the sociocultural influence, including acculturation and guiding principles of the Korean culture. A study with KA males reported that smoking was a means for social interaction. ${ }^{28)}$ Even though these KA individuals were not living in South Korea, the presence of cultural pressure to fit in social groups was still elevated. For instance, a separate study demonstrated the importance of the social context after finding that KA emerging adults are more likely to smoke in the presence of other Korean friends and while socializing. The presence of collectivism is also evident in the ways KA men talk about smoking rituals, as well as in the belief that quitting smoking would entail the loss of social ties. ${ }^{65)}$ Fortunately, according to a focus-group analysis of 11 current smokers and 11 former smokers, many KA smokers believe that smoking cessation is easier in the United States than in Korea. ${ }^{28)}$

Since household and workplace smoking bans are very common in the United States, a cross-sectional study evaluated the relationship between household smoking restrictions and intention to quit ${ }^{66)}$ and reported a significant association between these variables. However, the study also reported that cohabitation with other smokers, age, and a lower percentage of life spent in the United States were associated with lower intention or lower likelihood of quitting smoking.

While some studies partly focus on KA men, due to the high smoking rate in this population, other studies have focused on Korean American emerging adults (KAEA). KAEA comprise a high-risk population due to the presence of additional challenges to cessation, such as exploration of social identity, acculturation, and other factors related to development. A study that investigated perceived smoking prevalence among KAEA found that overestimation of the smoking prevalence was common, especially among females. ${ }^{64)}$ This finding is important because some individuals, especially emerging adults, adopt norms and behaviors that they perceive to share as a social identity. Therefore, in many populations, including KAs, perceived smoking among friends and peers is closely related to the current and future smoking behaviors.

A planned study with KA smokers will involve the implementation of a just-in-time adaptive intervention (JITAI) ${ }^{67)}$ JITAIs are personalized and administered in real-time. Thus, due to their flexibility, they are easily tailored for specific populations such as KAEA. ${ }^{67)}$ Partly based on data of focus-group analyses, the design of a JITAI for smoking cessation considers several decision points (i.e., moments in time when intervention is needed). In their process, the authors identified decision points, intervention options, and tailored variables. Although this study will be conducted in the United States, the methodology can be easily adopted in South Korea.

Most above mentioned studies did not indicate the proportion of KAs who were born and raised in South Korea. However, KAs who are linguistically assimilated and have spent more than half their lives in the United States are more likely to have the intention to quit. ${ }^{66)}$ These findings point to the importance of cultural norms that play a role in the smoking prevalence among KA individuals who strongly identify with the Korean culture despite living in the United States.

\section{DISCUSSION}

The purpose of this narrative review was to summarize the extant liter- 
ature on smoking in South Korea. Smoking prevalence among males in South Korea is relatively high (40\%-50\%). ${ }^{3,7)}$ Many socioeconomic factors may contribute to South Korea's slow progress towards a smoke-free population. Unlike other countries, South Korean residents have a high reluctance regarding treatment seeking, which is a barrier to develop and study successful, large-scale cessation programs. Given the socioeconomic and cultural factors in South Korea, it is difficult to state whether smoking will decrease, as predicted by the SimSmoke model, or even increase, as might be expected if more women start smoking. ${ }^{5)}$

Many observational studies focused on the adolescent and female adult populations, as these are most targeted by TTCs and may be at increased risk of smoking. ${ }^{25,26)}$ Although Korean adolescents and women are at-risk populations, most interventional studies involved male participants. ${ }^{68)}$ This selection may be explained by the high availability of Korean male smokers in comparison with their female counterparts. The relative dearth of interventional studies may be explained by the recent anti-smoking drive in South Korea, as well as by the reluctance of Korean smokers to seek treatment.

Although there are many opportunities for smoking research in South Korea, some obstacles still exist. A dearth of interventional studies involving females indicates a difficulty to recruit female participants. When the presence of smoking is biologically verified by the cotinine test, there is a discrepancy between the results of smoking prevalence based on self-reports and cotinine levels in females. ${ }^{46)}$ Although the cotinine test is useful to detect smoking, its use is not feasible on a regular basis (e.g., when using EMA). In addition, stigma regarding smoking in females may need to be addressed at a cultural level, and this will likely require time and effort on the part of the South Korean government. Researchers should also consider the underreporting of smoking prevalence among females due to the stigma regarding smoking in this population.

Despite these obstacles, there are many directions for future research. EMA studies may work well in a technologically savvy population (such as the South Korean population), although this remains to be demonstrated. It is also a discrete way of repeatedly assessing smoking behaviors and related factors, which may be appealing to females, in particular. Related research on smoking in South Korea can benefit from leveraging mobile technology. In South Korea, the rate of smartphone users is one of the highest in the world (83.3\%). More than $90 \%$ of individuals aged less than 60 years and more than $60 \%$ of individuals older than 60 years own a smartphone. ${ }^{69)}$ In this scenario, it is possible to design smartphone-based interventions to reduce the prevalence of smoking in Korea. A previous research suggests that smartphone-based interventions could be effective for smoking cessation. ${ }^{70)}$

Smartphone-based interventions could use targeted and tailored approaches, which provide individuals with personalized information. Although not in the context of smartphone-based interventions, several meta-analyses have documented the effects of tailored and personalized interventions. ${ }^{71,72)}$ For print messages (not delivered by smartphone), a meta-analysis found that tailored messages resulted in greater behavioural change than non-tailored messages. ${ }^{73)}$ Additionally, for web-based interventions, other meta-analysis found that tailored interventions are more effective than non-tailored interventions at immediate post-tests as well as follow-up tests. ${ }^{71)}$

Unfortunately, commercially available smartphone apps do not typically include tailored strategies, even though those that do it are preferred by users due to their greater popularity and higher user ratings. ${ }^{73)}$ Based on the content analysis of Hoeppner et al. ${ }^{73)}$ smartphone-based interventions for smoking cessation could tailor information according to the 5 As (ask, advise, assess, assist, and arrange follow-up). These types of tailored information could be provided by tools such as EMA and EMI.

As noted earlier, a limitation of the present study is that all reviewed articles were published in English and papers published in other languages, including Korean, were not represented. Although a narrative review does not need to be extensive, the limitations of the selection criteria adopted here should be borne in mind, including the potential for content bias.

\section{CONCLUSION}

In conclusion, smoking behavior and smoking cessation have been relatively understudied in South Korean smokers when compared to those in the United States and other Western countries. Future research should prioritize randomized control trials and female recruitment, and also take advantage of mobile technologies for conducting large sample EMA and EMI studies.

\section{CONFLICT OF INTEREST}

No potential conflict of interest relevant to this article was reported.

\section{ORCID}

Rebekah Gunter: https://orcid.org/0000-0002-7315-2238

Edwin Szeto: https://orcid.org/0000-0001-8879-0892

Se-Hoon Jeong: https://orcid.org/0000-0003-2411-5649

Sooyeon (Aly) Suh: https://orcid.org/0000-0003-0644-8634

Andrew J. Waters: https://orcid.org/0000-0002-0550-2961

\section{REFERENCES}

1. Stewart R. Beneath the surface: the global and local burden of tobacco use [Internet]. Seattle (WA): Institute for Health Metrics and Evaluation; 2017 [cited 2017 Sep 20]. Available from: http://www.healthdata. org/newsletters/impact-10/beneath-the-surface.

2. Ng M, Freeman MK, Fleming TD, Robinson M, Dwyer-Lindgren L, Thomson B, et al. Smoking prevalence and cigarette consumption in 187 countries, 1980-2012. JAMA 2014;311:183-92.

3. World Health Organization. WHO report on the global tobacco epidemic [Internet]. Geneva: World Health Organization; 2017 [cited 
2018 Aug 8]. Available from: http://www.who.int/tobacco/surveillance/policy/country_profile/kor.pdf?ua=1.

4. U.S. Department of Health and Human Services. The health consequences of smoking: 50 years of progress: a report of the Surgeon General. Atlanta (GA): U.S. Department of Health and Human Services, Centers for Disease Control and Prevention, National Center for Chronic Disease Prevention and Health Promotion, Office on Smoking and Health; 2014.

5. Levy DT, Cho SI, Kim YM, Park S, Suh MK, Kam S. SimSmoke model evaluation of the effect of tobacco control policies in Korea: the unknown success story. Am J Public Health 2010;100:1267-73.

6. Jemal A, Bray F, Center MM, Ferlay J, Ward E, Forman D. Global cancer statistics. CA Cancer J Clin 2011;61:69-90.

7. Organization for Economic Cooperation and Development. Daily smokers (indicator). Paris: Organization for Economic Cooperation and Development; 2017.

8. Hong JW, Noh JH, Kim DJ. The prevalence of and factors associated with urinary cotinine-verified smoking in Korean adults: the 20082011 Korea National Health and Nutrition Examination Survey. PLoS One 2018;13:e0198814.

9. Korea Centers for Disease Control and Prevention. Korea National Health and Nutrition Examination Survey: major results [Internet]. Cheongju: Korea Centers for Disease Control and Prevention [cited 2018 Aug 8]. Available from: https://knhanes.cdc.go.kr/knhanes/eng/ index.do.

10. White KM. Longevity advances in high-income countries, 1955-96. Popul Dev Rev 2002;28:59-76.

11. International cigarette prices [Internet]. [place unknown]: cigaretteprices.net; 2017 [cited 2017 May 28]. Available from: http://www.cigaretteprices.net/.

12. Lee S, Kimm H, Yun JE, Jee SH. Public health challenges of electronic cigarettes in South Korea. J Prev Med Public Health 2011;44:235-41.

13. Nakamura K, Huxley R, Ansary-Moghaddam A, Woodward M. The hazards and benefits associated with smoking and smoking cessation in Asia: a meta-analysis of prospective studies. Tob Control 2009;18:345-53.

14. Lee ES, Seo HG. The factors associated with successful smoking cessation in Korea. J Korean Acad Fam Med 2007;28:39-44.

15. Caponnetto P, Polosa R. Common predictors of smoking cessation in clinical practice. Respir Med 2008;102:1182-92.

16. Kaur J, Rinkoo AV. Getting real with the upcoming challenge of electronic nicotine delivery systems: the way forward for the South-East Asia region. Indian J Public Health 2017;61(Supplement):S7-S11.

17. Kasulis K. The South Korean government tried to scare smokers into quitting: but a fashion trend erupted. Mic [Internet]. 2018 Mar 15 [cited 2018 Mar 18]. Available from: https://mic.com/articles/188454/ the-south-korean-government-tried-to-scare-smokers-into-quittingbut-a-fashion-trend-erupted\#.zHbtOrFvZ.

18. Lee SG. Assessing impacts of the WHO FCTC on national legislations: a case study of the Republic of Korea. Health Policy 2017;121:604-12.

19. Lim MK, Cho HJ. Current status of tobacco control policies in Korea compared with international treaty and its implementation. J Korean Med Assoc 2018;61:148-56.

20. Khang $\mathrm{YH}, \mathrm{Cho} \mathrm{HJ}$. Socioeconomic inequality in cigarette smoking: trends by gender, age, and socioeconomic position in South Korea,
1989-2003. Prev Med 2006;42:415-22.

21. Ayers JW, Hofstetter CR, Hughes SC, Park HR, Paik HY, Song YJ, et al. Gender modifies the relationship between social networks and smoking among adults in Seoul, South Korea. Int J Public Health 2010;55:609-17.

22. Cho HJ, Khang YH, Jun HJ, Kawachi I. Marital status and smoking in Korea: the influence of gender and age. Soc Sci Med 2008;66:609-19.

23. Kim YN, Cho YG, Kim CH, Kang JH, Park HA, Kim KW, et al. Socioeconomic indicators associated with initiation and cessation of smoking among women in Seoul. Korean J Fam Med 2012;33:1-8.

24. Korean National Statistical Office. Youth statistics [Internet]. Daejeon: Statistics Korea; 2007 [cited 2017 Sep 5]. Available from: http://kostat. go.kr/portal/eng/pressReleases/13/3/index.board.

25. Lee K, Carpenter C, Challa C, Lee S, Connolly GN, Koh HK. The strategic targeting of females by transnational tobacco companies in South Korea following trade liberalization. Global Health 2009;5:2.

26. Lee S. The tobacco industry in South Korea since market liberalisation: implications for strengthening tobacco control [dissertation]. London: London School of Hygiene \& Tropical Medicine; 2011.

27. Allem JP, Ayers JW, Irvin VL, Hofstetter CR, Hovell MF. South Korean military service promotes smoking: a quasi-experimental design. Yonsei Med J 2012;53:433-8.

28. Kim SS, Son H, Nam KA. The sociocultural context of Korean American men's smoking behavior. West J Nurs Res 2005;27:604-23.

29. Central Intelligence Agency. The world factbook: East \& South East Asia: Korea, South [Internet]. Washington (DC): Central Intelligence Agency; 2010 [cited 2017 Sep 5]. Available from: https://www.cia.gov/ library/publications/the-world-factbook/wfbExt/region_eas.html .

30. Shiffman S, Waters AJ. Negative affect and smoking lapses: a prospective analysis. J Consult Clin Psychol 2004;72:192-201.

31. Peng K, Nisbett RE. Culture, dialectics, and reasoning about contradiction. Am Psychol 1999;54:741-54.

32. Chen FF, Bai L, Lee JM, Jing Y. Culture and the structure of affect: a bifactor modeling approach. J Happiness Stud 2016;17:1801-24.

33. Napa Scollon C, Diener E, Oishi S, Biswas-Diener R. An experience sampling and cross-cultural investigation of the relation between pleasant and unpleasant affect. Cogn Emot 2005;19:27-52.

34. Morrison A, Polisena J, Husereau D, Moulton K, Clark M, Fiander M, et al. The effect of English-language restriction on systematic reviewbased meta-analyses: a systematic review of empirical studies. Int J Technol Assess Health Care 2012;28:138-44.

35. Gold DR, Wang X, Wypij D, Speizer FE, Ware JH, Dockery DW. Effects of cigarette smoking on lung function in adolescent boys and girls. $\mathrm{N}$ Engl J Med 1996;335:931-7.

36. Choi S, Kim Y, Park S, Lee J, Oh K. Trends in cigarette smoking among adolescents and adults in South Korea. Epidemiol Health 2014;36:e2014023.

37. Hwang JH, Park SW. Age at smoking initiation and subsequent smoking among Korean adolescent smokers. J Prev Med Public Health 2014;47:266-72.

38. U.S. Department of Health and Human Services. Preventing tobacco use among young people: a report of the Surgeon General. [Internet]. Washington (DC): Office of the Surgeon General, U.S. Department of Health and Human Services; 1994 [cited 2018 Sep 5]. Available from: https://www.surgeongeneral.gov/library/reports/preventing-youth- 
tobacco-use/index.html.

39. Lee WT, Kim HI, Kim JH, Lee SJ, Hong S, Park EC. Relationships between body image, body mass index, and smoking in Korean adolescents: results of a nationwide Korea Youth Risk Behavior Web-based Survey. Asian Pac J Cancer Prev 2015;16:6273-8.

40. Jung J, Lee SH. Cross-cultural comparisons of appearance self-schema, body image, self-esteem, and dieting behavior between Korean and US women. Fam Consum Sci Res J 2006;34:350-65.

41. Joung MJ, Han MA, Park J, Ryu SY. Association between family and friend smoking status and adolescent smoking behavior and e-cigarette use in Korea. Int J Environ Res Public Health 2016;13:E1183.

42. Heo J, Oh J, Subramanian SV, Kawachi I. Household and school-level influences on smoking behavior among Korean adolescents: a multilevel analysis. PLoS One 2014;9:e98683.

43. Cui X, Rockett IR, Yang T, Cao R. Work stress, life stress, and smoking among rural-urban migrant workers in China. BMC Public Health 2012;12:979.

44. Huh J, Shin H, Leventhal AM, Spruijt-Metz D, Abramova Z, Cerrada C, et al. Momentary negative moods and being with friends precede cigarette use among Korean American emerging adults. Nicotine Tob Res 2014;16:1248-54.

45. Kim K, Park H. Gender differences in the association between self-reported stress and cigarette smoking in Korean adolescents. Tob Induc Dis 2016;14:19.

46. Jung-Choi KH, Khang YH, Cho HJ. Hidden female smokers in Asia: a comparison of self-reported with cotinine-verified smoking prevalence rates in representative national data from an Asian population. Tob Control 2012;21:536-42.

47. Kang HG, Kwon KH, Lee IW, Jung B, Park EC, Jang SI. Biochemicallyverified smoking rate trends and factors associated with inaccurate self-reporting of smoking habits in Korean women. Asian Pac J Cancer Prev 2013;14:6807-12.

48. Jhun HJ, Seo HG. The stages of change in smoking cessation in a representative sample of Korean adult smokers. J Korean Med Sci 2006;21:843-8.

49. Prochaska JO, DiClemente CC. Toward a comprehensive model of change: treating addictive behaviors. Boston (MA): Springer; 1986.

50. Sohn M, Stotts NA, Benowitz N, Christopherson D, Kim KS, Jang YS, et al. Beliefs about health, smoking, and future smoking cessation among South Korean men hospitalized for cardiovascular disease. Heart Lung 2007;36:339-47.

51. Shiffman S, Stone AA, Hufford MR. Ecological momentary assessment. Annu Rev Clin Psychol 2008;4:1-32.

52. Kim CH, Song HR, Lee WS, Kim JY. Attitudes toward smoking cessation intervention and services among Korean physicians: a questionnaire survey. Korean J Fam Med 2009;30:857-63.

53. Vangeli E, Stapleton J, Smit ES, Borland R, West R. Predictors of attempts to stop smoking and their success in adult general population samples: a systematic review. Addiction 2011;106:2110-21.

54. Choi WY, Kim CH, Lee OG. Effects of brief smoking cessation education with expiratory carbon monoxide measurement on level of motivation to quit smoking. Korean J Fam Med 2013;34:190-8.

55. Lee JE, Shin DW, Suh B, Chun S, Nam YS, Cho B. Development and application of culturally appropriate decision aids for smoking cessation in Korea: a pragmatic clustered randomization crossover trial. Pa- tient Prefer Adherence 2016;10:1929-36.

56. Kim SR, Kim HK, Kim JY, Kim HY, Ko SH, Park M. Smoking cessation failure among Korean adolescents. J Sch Nurs 2016;32:155-63.

57. Myung SK, Seo HG, Park EC, Lim MK, Kim Y. An observational study of the Korean proactive quitline service for smoking cessation and relapse prevention. Public Health Rep 2011;126:583-90.

58. Sohn M, Jung M. Effect of viewing smoking scenes in motion pictures on subsequent smoking desire in audiences in South Korea. JMIR Public Health Surveill 2017;3:e46.

59. Cheng HM, Chung YC, Chen HH, Chang YH, Yeh ML. Systematic review and meta-analysis of the effects of acupoint stimulation on smoking cessation. Am J Chin Med 2012;40:429-42.

60. White AR, Rampes H, Liu JP, Stead LF, Campbell J. Acupuncture and related interventions for smoking cessation. Cochrane Database Syst Rev 2014;(1):CD000009.

61. Kang OS, Kim SY, Jahng GH, Kim H, Kim JW, Chung SY, et al. Neural substrates of acupuncture in the modulation of cravings induced by smoking-related visual cues: an fMRI study. Psychopharmacology (Berl) 2013;228:119-27.

62. Heron KE, Smyth JM. Ecological momentary interventions: incorporating mobile technology into psychosocial and health behaviour treatments. Br J Health Psychol 2010;15(Pt 1):1-39.

63. Joo NS, Kim BT. Mobile phone short message service messaging for behaviour modification in a community-based weight control programme in Korea. J Telemed Telecare 2007;13:416-20.

64. Cerrada CJ, Unger JB, Huh J. Correlates of perceived smoking prevalence among Korean American emerging adults. J Immigr Minor Health 2016;18:1183-9.

65. Cerrada CJ, Ra CK, Shin HS, Dzubur E, Huh J. Using ecological momentary assessment to identify common smoking situations among Korean American emerging adults. Prev Sci 2016;17:892-902.

66. Myung SK, McDonnell DD, Kazinets G, Seo HG, Moskowitz JM. Relationships between household smoking restrictions and intention to quit smoking among Korean American male smokers in California. J Korean Med Sci 2010;25:245-50.

67. Cerrada CJ, Dzubur E, Blackman KC, Mays V, Shoptaw S, Huh J. Development of a just-in-time adaptive intervention for smoking cessation among Korean American emerging adults. Int J Behav Med 2017;24: $665-72$.

68. Hwang GS, Jung HS, Yi Y, Yoon C, Choi JW. Smoking cessation intervention using stepwise exercise incentives for male workers in the workplace. Asia Pac J Public Health 2012;24:82-90.

69. Korea Communications Commission. Broadcast media usage behavior [Internet]. Gwacheon: Korea Communications Commission; 2016 [cited 2017 Sep 3]. Available from: http://www.kcc.go.kr/user.do? mode $=$ view $\&$ page $=$ A02160000 $\&$ dc $=$ K00000001\&boardId $=1022 \&$ boa $\mathrm{rdSeq}=44436$.

70. Bricker JB, Mull KE, Kientz JA, Vilardaga R, Mercer LD, Akioka KJ, et al. Randomized, controlled pilot trial of a smartphone app for smoking cessation using acceptance and commitment therapy. Drug Alcohol Depend 2014;143:87-94.

71. Lustria ML, Noar SM, Cortese J, van Stee SK, Glueckauf RL, Lee J. A meta-analysis of web-delivered tailored health behavior change interventions. J Health Commun 2013;18:1039-69.

72. Noar SM, Benac CN, Harris MS. Does tailoring matter?: meta-analytic 
review of tailored print health behavior change interventions. Psychol Bull 2007;133:673-93.

73. Hoeppner BB, Hoeppner SS, Seaboyer L, Schick MR, Wu GW, Berg- man BG, et al. How smart are smartphone apps for smoking cessation?: a content analysis. Nicotine Tob Res 2016;18:1025-31. 